\title{
CRYSTAL STABILITY OF THE PHASE Ca2Fe205 WHEN USED IN HETEROGENEOUS PHOTOCATALYSIS
}

\author{
da Silva, E. B.*; Valentini, A.
}

Department of Analytical Chemistry and Physical Chemistry, Federal University of Ceará, Fortaleza, Ceará, Brazil

*erandirbrasildasilva@yahoo.com.br

In the field of academic study has been proposed to use $\mathrm{Ca}_{2} \mathrm{Fe}_{2} \mathrm{O}_{5}$ phase as applicable material in heterogeneous photocatalysis for degradation of organic compounds such as dyes. However, it is unclear the real applicability of this compound and little is known about the phase stability under reaction conditions. Thus, a suitable study is necessary, the interaction of this crystalline phase with carbon dioxide in aqueous solution. By means of monitoring of structural composition using X-ray diffraction, before and after various reaction conditions with the change of the bubbling gas used in the reaction system, was verified low stability of $\mathrm{Ca}_{2} \mathrm{Fe}_{2} \mathrm{O}_{5}$ phase under reaction conditions, when applied on the degradation of dyes in aqueous system. Lower conversion efficiency was observed when the process was carried out in the presence of $\mathrm{CO}_{2}$; although, the instability of $\mathrm{Ca}_{2} \mathrm{Fe}_{2} \mathrm{O}_{5}$ phase was observed also under $\mathrm{N}_{2}$, air or $\mathrm{CO}_{2}$. The degradation of the crystalline phase $\mathrm{Ca}_{2} \mathrm{Fe}_{2} \mathrm{O}_{5}$ (orthorhombic) occurs in a complete way in a short reaction time. The XRD patterns pointed out the $\mathrm{CaCO}_{3}$ phase formation, additionally suggest the formation of $\mathrm{FeO}(\mathrm{OH})$ and $\mathrm{CaFe}_{2} \mathrm{O}_{4}$ phases. 